\title{
Gesture Therapy: An upper limb virtual reality-based motor rehabilitation platform
}

\author{
Luis Enrique Sucar, Senior Member, IEEE, Felipe Orihuela-Espina, Roger Luis Velazquez, \\ David J. Reinkensmeyer, Member, IEEE, Ronald Leder, Senior Member, IEEE, and Jorge Hernández-Franco,
}

\begin{abstract}
Virtual reality platforms capable of assisting rehabilitation must provide support for rehabilitation principles: promote repetition, task oriented training, appropriate feedback and a motivating environment. As such, development of these platforms is a complex process which has not yet reached maturity. This paper presents our efforts to contribute to this field, presenting Gesture Therapy, a virtual reality-based platform for rehabilitation of the upper limb. We describe the system architecture and main features of the platform and provide preliminary evidence of the feasibility of the platform in its current status.
\end{abstract}

Index Terms-Rehabilitation, virtual reality, serious games, stroke.

\section{INTRODUCTION}

$\mathbf{I}$ NDIVIDUALS with motor impairment undergo rehabilitation therapy in order to fully or partially recover their mobility and psycho-social health. The former is restored by motor rehabilitation therapies which aim at alleviating motor impairment and boosting the patient's quality of life. A large range of different interventions are available depending on treatment components incorporated [1], including constraint induced movement therapy, electromyographic biofeedback, electromechanical assisted training, electrostimulation, high intensity therapy, robotics, repetitive task training, splinting and physical fitness training among others. Recently other approaches have began to flourish such as music-supported therapy, telerehabilitation, and virtual reality (VR)-based therapies.

Gesture Therapy (GT) is a novel virtual reality-based platform for upper limb rehabilitation aimed at lower or middle income countries and home usage [2]-[4]. Similarly to other existing virtual reality-based platforms, GT disguises the rehabilitation exercises as actions within computer games. GT differentiates from its counterparts in aspects such as the specially designed controllers, and the use of artificial intelligence probabilistic decision models for guiding the therapy. This paper describes the GT platform and present kinematic data from a recent feasibility pilot. Technological contributions include specifically designed controllers, a 3D monocular tracking system and an adaptation algorithm for optimizing game challenge according to patient's performance. Clinical contributions include further evidence of the usefulness and validity of virtual reality based therapies and an assessment

Luis Enrique Sucar (corresponding author) is with the Department of Computing, National Institute for Astrophysics, Optics and Electronics (INAOE), Puebla, 72840 Mexico e-mail: esucar@ccc.inaoep.mx.

Manuscript received July 19, 2012; revised Sep 19, 2012. of the neuroplastic changes associated to this therapy. Part of this paper overviews work previously published in conference paper format [2]-[5]. In addition, we further present here the new game set.

\section{VIRTUAL REALITY FOR MOTOR REHABILITATION}

Principles thought to encourage effective rehabilitation are:

- Repetition: In contrast with evidence that more practice is better [6] and that purposeful movements is an integral part of improving functional status, repetitions during common physical and occupational therapy are not enough and those of purposeful movements are economized [7]. New assistive technologies such as VR potentially allow patients to practice more intensively on their own [6], but to date no study has demonstrated this increment in practice on the patient's own when using VR.

- Feedback: Feedback improves learning rate and is of utmost importance for motor learning [8]. Feedback evokes neurophysiological processes that induce profound cortical and subcortical changes. In general, computer games excel at providing feedback [8] further contributing to keep the player engaged [9]. Notwithstanding, the potential of VR to provide more and better feedback to the user remains to be fulfilled with only a few studies to date having demonstrated the added value of feedback delivered through VR [10].

- Motivation: Patient motivation is central to exercise adherence [11], [12]. Variation in the game, challenge and competition are elements that can enhance motivation [12]. Rehabilitation games can motivate patients by connecting them with friends and family giving them and sense of social connectedness [13].

- Task oriented training: Functional reorganization of the motor cortex (remapping), in the rat and the primate, occurs only in response to development of skilled forelimb movements, and not simply to increased forelimb use [8]. In humans, task oriented training using VR has already demonstrated its usefulness for fractionation, the ability to move each finger individually in isolation [14], [15].

\section{A. Pros and cons of virtual reality based motor rehabilitation}

A number of potential benefits of virtual reality-based motor rehabilitation therapies are recurrently claimed in the literature. First, virtual reality-based rehabilitation has shown validity by complying with the key principles in rehabilitation 
outlined above. Second, virtual reality-based rehabilitation can be adapted to the user need and progress. The dose, frequency, challenge, task variability, etc. are easily modifiable in a virtual environment. Third, virtual reality-based rehabilitation may be customized to the therapy requirements. It can be tailored for different pathophysiologies and/or different target groups. Fourth, virtual reality-based rehabilitation theoretically could require low clinical supervision facilitating home use [16], saving costs [17], enabling telerehabilitation [17], and opening opportunities to practise everyday activities that cannot be practised within the hospital environment [18]. A few other benefits have also been suggested. These include low cost, quick development, less dangerous in certain applications or flexible schedule. Also distractors may be eliminated or added on demand, complex tasks can be decomposed into simpler tasks, and systems have wide testing capabilities (methodologies, feedback forms, timings, regulatory conditions, etc). They facilitate increased standardization of assessment and treatment protocols, as well as permit objective measurement of behaviour and performance. Finally, well designed virtual environments can provide enhanced ecological validity when compared with traditional rehabilitation tasks [19]. The evidence supporting these benefits is still being developed.

Of course, it also has some drawbacks. The systems often require specialist expertise to set up and operate [9]. Immersive systems may be accompanied by cybersicknesses [20]. Patients may be unfamiliar with computer games and the whole virtual reality environment [9], and these games are not necessarily enjoyed by everyone.

\section{B. Learning in virtual environments versus learning in real environments}

Rose et al [21] have suggested that virtual environments may (i) stimulate neuroplastic changes, (ii) enhance learning and problem solving, and (iii) reduce cognitive impairment. Humans can learn motor skills in a virtual environment and they can transfer that motor learning to a real world environment [8]. Even patients with significant motor and cognitive impairment are capable of at least some learning within a virtual reality environment [8]. Evidence from a variety of learning conditions in healthy subjects and a small amount of evidence in patient populations suggest that there is a positive transfer from virtual to real environments [22][26], even though the extent of the transfer and the particular elements and conditions that facilitate the transfer are not yet fully understood [23].

\section{Existing VR platforms for upper limb rehabilitation}

In the last decade, a number of virtual reality based rehabilitation platforms have been developed. Table I provides an overview of academic and commercial virtual reality based rehabilitation solutions for the upper limb. Despite advances, the full potential of a rehabilitation therapy based on virtual reality has not yet been realized, and there is still much room for improvements.

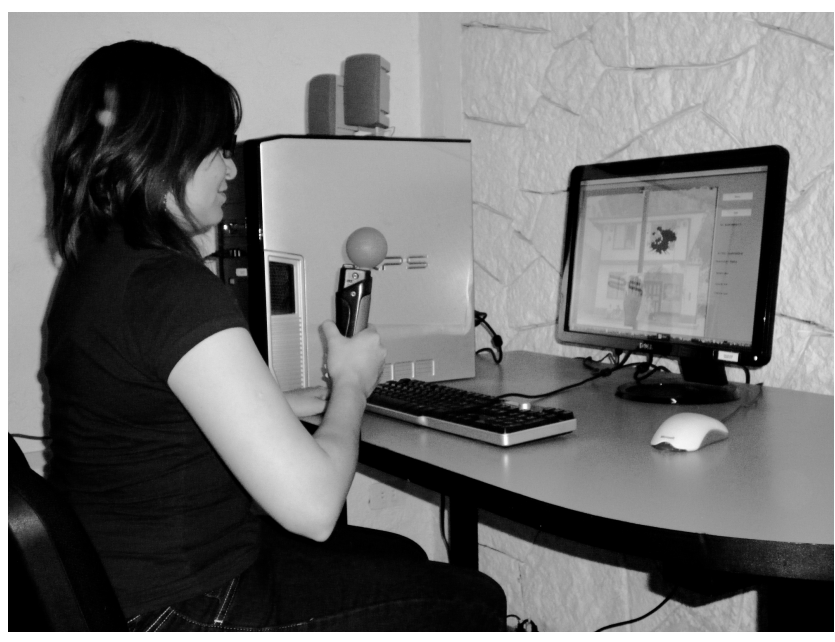

Fig. 1. The Gesture Therapy platform. The webcam tracks hand/gripper movements and translate that into commands to control the games. In addition the pressure sensor incorporated in the gripper facilitates hand training.

\section{Gesture Therapy}

Gesture therapy (GT) [2]-[4] is a virtual reality based motor rehabilitation therapy which favours the principles of rehabilitation described above (repetition, feedback, motivation and task specific training) by challenging the patient to fulfill daily tasks in a safe virtual environment (see Fig. 1). The tasks are presented in the form of short serious games. Earlier trials [4], [5] suggest that Gesture Therapy provides measurable improvements in motor dexterity comparable to more classical occupational therapy but with an edge on motivation. Conceptually, the GT platform consists of five interacting modules:

- Physical System: Encompasses the hardware platform incorporating a computer (Windows or Unix), a webcam and controllers e.g. a handgrip, further described below. GT has been developed targeting home usage and as such one of its most important features is its low cost. The system hardware is specially chosen to keep cost to a minimum, and The complete set of equipment costs less than 1000USD with the computer being the most expensive part.

- Tracking System: This is the software responsible for tracking the handgrip; proxy of arm movement. The software receives information from both the monocular tracking system (i.e. webcam) and the controller. The monocular tracking system provides the location of the gripper, and pressure data is obtained from the controller [2], [3]. Often, it will be the coloured ball on the top of the handgrip which will be tracked since the distinctive colour of this ball facilitates the tracking. However, as further described below, the tracking system is not hard linked to tracking the handgrip; the target for tracking is selected during the training stage of the tracking system and thus the hand of the user i.e. the patient, can be tracked directly if desired.

- Simulated Environment: The central module of the platform is responsible for presenting the game and 
TABLE I

SUMMARY OF VIRTUAL REHABILITATION SOLUTIONS FOR THE UPPER LIMB BY YEAR OF PUBLICATION. PURELY ROBOTIC SOLUTIONS SUCH AS THAT IN [27] OR THE MIME SYSTEM [28] ARE NOT INCLUDED, BUT HYBRID SYSTEMS USING VIRTUAL REALITY ARE INCLUDED, E.G. MIT MANUS .

\begin{tabular}{|c|c|c|c|}
\hline Name, Ref. \& Year & Brief Description & Virtual Environments & Clinical Trials \& Case studies \\
\hline $\begin{array}{lll}\text { Driver's } \\
(1999)\end{array}$ & $\begin{array}{l}\text { A } 1 \text { degrees of freedom (dof) } \\
\text { steering wheel }\end{array}$ & $\begin{array}{l}\text { Driving (rural, suburban and ur- } \\
\text { ban) }\end{array}$ & Not described \\
\hline $\begin{array}{l}\text { MIT Manus }[30] \\
(1998)\end{array}$ & $\begin{array}{l}\text { Robotic platform including a pla- } \\
\text { nar module }(2 \text { dof }) \text { and a wrist } \\
\text { module ( } 3 \text { dof }) \text { with armrest }\end{array}$ & $\begin{array}{l}\text { Drawing circles, stars, squares } \\
\text { and diamonds, and navigating } \\
\text { through windows }\end{array}$ & $\begin{array}{l}\text { Robotic training additional to standard therapy } \\
\text { improves motor recovery. The improved outcome } \\
\text { was sustainable over } 3 \text { years }\end{array}$ \\
\hline $\begin{array}{l}\text { Rutgers orthopedic } \\
\text { telerehabilitation } \\
\text { system [16] }(2000)\end{array}$ & $\begin{array}{l}\text { Input device is the "Rutgers Mas- } \\
\text { ter" glove for the hand. }\end{array}$ & $\begin{array}{l}\text { Games; Power putty, digikey, } \\
\text { peg board, hand ball }\end{array}$ & $\begin{array}{l}\text { It demonstrated improvements in terms of range } \\
\text { of motion, velocity, fractionation and thumb } \\
\text { strength in case studies }\end{array}$ \\
\hline $\begin{array}{l}\text { ARM Guide [31] } \\
(2000)\end{array}$ & $\begin{array}{l}\text { Passive linear constraint with } 1 \\
\text { dof motor exoskeleton }\end{array}$ & $\begin{array}{l}\text { Reaching task. Feedback is pro- } \\
\text { vided in video monitor. }\end{array}$ & $\begin{array}{l}\text { Several case studies suggests increments in reach } \\
\text { and velocity plus a reduction in tone. }\end{array}$ \\
\hline $\begin{array}{l}\text { Java Therapy }[32] \\
(2001)\end{array}$ & $\begin{array}{l}\text { Force feedback joystick with web } \\
\text { based games. Requires armrest. }\end{array}$ & $\begin{array}{l}\text { Games inc. Breakout, othello, } \\
\text { torpedo and tail gunner }\end{array}$ & A case study is inconclusive [17] \\
\hline $\begin{array}{l}\text { Virtual Environment } \\
\text { Training System [33] } \\
\text { (2002) }\end{array}$ & $\begin{array}{l}\text { A desktop display and elec- } \\
\text { tromagnetic motion-tracking de- } \\
\text { vices }\end{array}$ & $\begin{array}{l}\text { Putting envelope in mailbox. } \\
\text { Reaching exercises. }\end{array}$ & $\begin{array}{l}\text { A small cohort }(\mathrm{n}=9) \text { exhibited improvements } \\
\text { (15\% in Fugl-Meyer and } 31 \% \text { in Wolf Motor } \\
\text { Test }) \text { in } 2 \text { reaching movements. }\end{array}$ \\
\hline TheraJoy [34] (2002) & $\begin{array}{l}\text { Modified mass-marketed force } \\
\text { feedback joystick }\end{array}$ & $\begin{array}{l}\text { Games are used but no further } \\
\text { details provided }\end{array}$ & Not described \\
\hline Gentle/s [35] (2003) & $\begin{array}{l}\text { Large screen with a } 3 \text { dof haptic } \\
\text { interface. }\end{array}$ & $\begin{array}{l}\text { Empty room, real room and de- } \\
\text { tail room. }\end{array}$ & $\begin{array}{l}\text { Requires elbow orthosis. The system was able to } \\
\text { motivate people. }\end{array}$ \\
\hline $\begin{array}{l}\text { TheraDrive } \\
\text { (2004) }\end{array}$ & Force-feedback steering wheel & $\begin{array}{l}\text { SmartDriver (Commercial driv- } \\
\text { ing videogame) }\end{array}$ & $\begin{array}{l}\text { Clinical benefits in terms of motor performance } \\
\text { and an edge on motivation }\end{array}$ \\
\hline $\begin{array}{l}\text { GestureTek's GX and } \\
\text { IREX platforms [37] } \\
\text { (2004) }\end{array}$ & $\begin{array}{l}\text { Video capture VR system }+ \\
\text { gloves }+ \text { large screen }\end{array}$ & $\begin{array}{l}\text { Games inc. soccer, birds and } \\
\text { balls and snowboard }\end{array}$ & $\begin{array}{l}\text { Balance improvements similar to conventional } \\
\text { therapy, but with increased enjoyment. IREX } \\
\text { favours ipsilesional SM1 reactivation [38] }\end{array}$ \\
\hline $\begin{array}{l}\text { Sony PlayStation }+ \\
\text { EyeToy [37] }(2004)\end{array}$ & $\begin{array}{l}\text { Off-the-shelf video capture vir- } \\
\text { tual reality gaming platform }\end{array}$ & $\begin{array}{l}\text { Games inc. Knockout, Do it } \\
\text { yourself, Colors and Mr. Chef. }\end{array}$ & $\begin{array}{l}\text { A case study showed improvements in motor dex- } \\
\text { terity mainly due to major sensory improvements }\end{array}$ \\
\hline $\begin{array}{l}\text { VR Physical Therapy } \\
\text { [39] (2005) }\end{array}$ & $\begin{array}{l}\text { Data glove and games system for } \\
\text { telerehabilitation }\end{array}$ & $\begin{array}{l}\text { Games; Puzzles inc. Merlin's re- } \\
\text { venge }\end{array}$ & Not described \\
\hline $\begin{array}{l}\text { TheraGame } \quad[40] \\
(2006)\end{array}$ & $\begin{array}{l}\text { Video capture (Webcam) VR sys- } \\
\text { tem }\end{array}$ & $\begin{array}{l}\text { Games inc. Tetris, frog, color- } \\
\text { Sok and motion music }\end{array}$ & $\begin{array}{l}\text { Patient with neurological deficits found the sys- } \\
\text { tem engaging. }\end{array}$ \\
\hline T-WREX [41] (2006) & $\begin{array}{l}5 \text { dof exoskeleton (WREX) used } \\
\text { as 3D mouse }+ \text { a grip sensor }\end{array}$ & $\begin{array}{l}\text { shopping, } \\
\text { s) }\end{array}$ & $\begin{array}{l}\text { T-WREX is effective in enhancing UL motor } \\
\text { recovery and patient motivation. }\end{array}$ \\
\hline Xbox [42] (2006) & Modified Xbox + glove & $\begin{array}{l}2 \text { games; Butterfly/UFO scaring } \\
\text { and Clean up, shared with [43]. }\end{array}$ & Not described \\
\hline $\begin{array}{l}\text { ARMeo (Hocoma) } \\
{[31](2000-6)}\end{array}$ & $\begin{array}{l}\text { Passive linear constraint with } 1 \\
\text { dof motor. This is the commercial } \\
\text { version of [31] and [41] }\end{array}$ & $\begin{array}{l}\text { Games inc. Rain mug, fruit } \\
\text { shopping, egg cracking and re- } \\
\text { veal picture }\end{array}$ & Not described \\
\hline $\begin{array}{l}\text { Universities of Derby } \\
\text { and Ulster's serious } \\
\text { games [44] (2008) }\end{array}$ & $\begin{array}{l}\text { Immersive head mounted display } \\
\text { (HMD) and gloves }\end{array}$ & $\begin{array}{l}\text { Games inc. Rabbit chase, ar- } \\
\text { row attack, orange catching, and } \\
\text { whack-a-mouse }\end{array}$ & $\begin{array}{l}\text { Small clinical trial suggested clinical benefits in } \\
\text { terms of motor performance that was sustained } 6 \\
\text { weeks after intervention }\end{array}$ \\
\hline $\begin{array}{l}\text { Play Station } 3[43] \\
(2008)\end{array}$ & PlayStation $3+$ glove & $\begin{array}{l}2 \text { games; Butterfly/UFO scaring } \\
\text { and Clean up, shared with [42]. }\end{array}$ & $\begin{array}{l}\text { Pilot study in children suggests some improve- } \\
\text { ments in ADL. }\end{array}$ \\
\hline Wii [45] (2008) & Wii & $\begin{array}{l}\text { s inc. Boxing, } \\
\text { nd golf }\end{array}$ & $\begin{array}{l}\text { A case study of palsy resulted in augmented reha- } \\
\text { bilitation when complementing physical therapy. }\end{array}$ \\
\hline $\begin{array}{l}\text { Elinor Game Platform } \\
\text { [46] (2009) }\end{array}$ & $\begin{array}{l}\text { A game console controlled with } \\
2 \text { handles }\end{array}$ & $\begin{array}{l}15 \text { games based on classical con- } \\
\text { cepts }\end{array}$ & $\begin{array}{l}\text { Case studies are not assessed clinically, but only } \\
\text { claimed to exhibit gamers behaviour. }\end{array}$ \\
\hline $\begin{array}{l}\text { Virtual Piano Trainer } \\
\text { [14] (2009) }\end{array}$ & $\begin{array}{l}\text { Virtual piano with cyberglove, } \\
\text { cybergrasp and two arm tracking } \\
\text { sensors }\end{array}$ & Virtual piano & $\begin{array}{l}\text { A pilot study suggested improvements in frac- } \\
\text { tionation }\end{array}$ \\
\hline iStretch [47] (2010) & $\begin{array}{l}1 \text { dof robotic system for the early } \\
\text { stages of physiotherapy }\end{array}$ & Reaching task & Not de \\
\hline $\begin{array}{l}\text { Adaptive Mixed Real- } \\
\text { ity Rehabilitation sys- } \\
\text { tem [48] (2010) }\end{array}$ & $\begin{array}{l}\text { A table with } 4 \text { target buttons }+ \\
\text { large screen }+2 \text { speakers }\end{array}$ & $\begin{array}{l}4 \text { different training environ- } \\
\text { ments: Virtual, hybrid I and II } \\
\text { and physical }\end{array}$ & $\begin{array}{l}\text { A pilot }(n=4) \text { showed significant improvement in } \\
\text { reaching and grasping performance compared to } \\
\text { controls under traditional therapy. }\end{array}$ \\
\hline $\begin{array}{lll}\text { None } & \text { given } & {[13]} \\
(2010)\end{array}$ & Wii based + vision system & $\begin{array}{l}8 \text { games inc. baseball catch, he- } \\
\text { licopter flying, frog Simon and } \\
\text { under-the-sea }\end{array}$ & Results with case studies were encouraging \\
\hline $\begin{array}{l}\text { Hadassah University } \\
\text { Hospital system [49] } \\
(2012)\end{array}$ & $\begin{array}{l}\text { A motion capture VR system in- } \\
\text { tegrating online self-face viewing } \\
\text { and mirror visual feedback }\end{array}$ & $\begin{array}{l}\text { Various game-like tasks; catch } \\
\text { money and pick fruit among oth- } \\
\text { ers }\end{array}$ & $\begin{array}{l}\text { A study }(\mathrm{n}=6) \text { demonstrated feasibility in terms } \\
\text { of adherence and improvement in task perfor- } \\
\text { mance }\end{array}$ \\
\hline $\begin{array}{l}\text { Art-empowered } \text { VR } \\
{[50](2013)}\end{array}$ & $\begin{array}{l}2 \text { large displays, a tracking sys- } \\
\text { tem of head and arm, and a pneu- } \\
\text { matically actuated glove }\end{array}$ & $\begin{array}{l}\text { March Hare's cottage environ- } \\
\text { ment }\end{array}$ & $\begin{array}{l}\text { Preliminary results ( } \mathrm{n}=4 \text { of } 9 \text { ) suggest grip and } \\
\text { pinch improvements. }\end{array}$ \\
\hline $\begin{array}{l}\text { Spatial Augmented } \\
\text { Reality [51] (2013) }\end{array}$ & $\begin{array}{l}\text { Computer, webcam, projector } \\
\text { and table for projection }\end{array}$ & $\begin{array}{l}4 \text { tasks; reaching, holding and } \\
\text { tilting, pointing and grasping }\end{array}$ & Two subjects feasibility pilot poorly described. \\
\hline $\begin{array}{l}\text { None given }[52] \\
(2013)\end{array}$ & $\begin{array}{l}\text { Hybrid; } 7 \text { dof passive robot } \\
\text { (Trackhold), VR and } 128 \text { chan- } \\
\text { nels EEG }\end{array}$ & $\begin{array}{l}5 \text { environments; sponge, bug } \\
\text { hunt, grab 2D, grab 3D and } \\
\text { Twirl }\end{array}$ & $\begin{array}{l}\text { Pilot }(\mathrm{n}=2) \text { demonstrated feasibility to monitor } \\
\text { neuro-motor recovery. lateralization. }\end{array}$ \\
\hline
\end{tabular}


interacting with the user. This module is in charge of providing the feedback to the user and the therapist. Currently visual and auditory feedback are available depending on the game. The module is also responsible for tracking progress through the therapy. A database stores information about patient interaction with the system. The in-game information is used by the adaptation module to adjust game difficulty in real time. Although a basic database already stores in-game information, we are currently working towards enlarging the database to include capabilities for inter-game information and user profiling.

- Trunk Compensation Detector: Trunk compensation is detected by tracking the user head using basic Haar features and a cascade of classifiers [53]. The compensation detector estimates trunk inclination by exploiting a limitation of the algorithm which fails to detect faces at untrained angles. Compensation is assumed to occur if inclination exceeds a threshold determined during training of the classifiers [4], i.e. when the classifiers fail to detect the face. Although this procedure assumes that the head moves in synchrony with the trunk during compensation, this assumption has proved empirically to be reasonably robust for practical purposes. Nonetheless, the underlying assumption that head and face tracking can provide reliable information on trunk displacement remains unproven, and in any case it shall represent a non causal association. After trunk compensation movement is detected, the system may provide an alarm or block the game. This functionality can be switched on and off on demand as the role of compensation may depend on the patient's progress [6], [54].

- Adaptation Module: This module is capable of adjusting the 3D space in which the exercise occurs. It uses ingame information to dynamically adjust the difficulty of the task. The system identifies user dexterity and adjusts the game difficulty accordingly capitalising on a partially observable Markov decision process (POMDP) [55]. Inter-game adaptation is part of the on-going work in our lab but has not yet been formally incorporated to the platform. The adaptation module is critical for relocating therapy sessions from rehabilitation centers to home, and also to decrease the need for on-site assistance of professional therapists.

\section{A. System architecture and implementation}

A schematic representation of the system architecture is illustrated in Fig. 2. Basically, a vision module gets the input video stream from the camera, as well as the pressure data from the controller. The vision module extracts arm and hand position from the video, and passes this information together with the pressure information to a game engine for game control. The game engine is responsible for the proper game rendering and behaviour. It further monitors user's speed and smoothness of trajectory which are communicated to the adaptation policy. The adaptation policy decides upon the best action to take regarding increasing/decreasing game difficulty

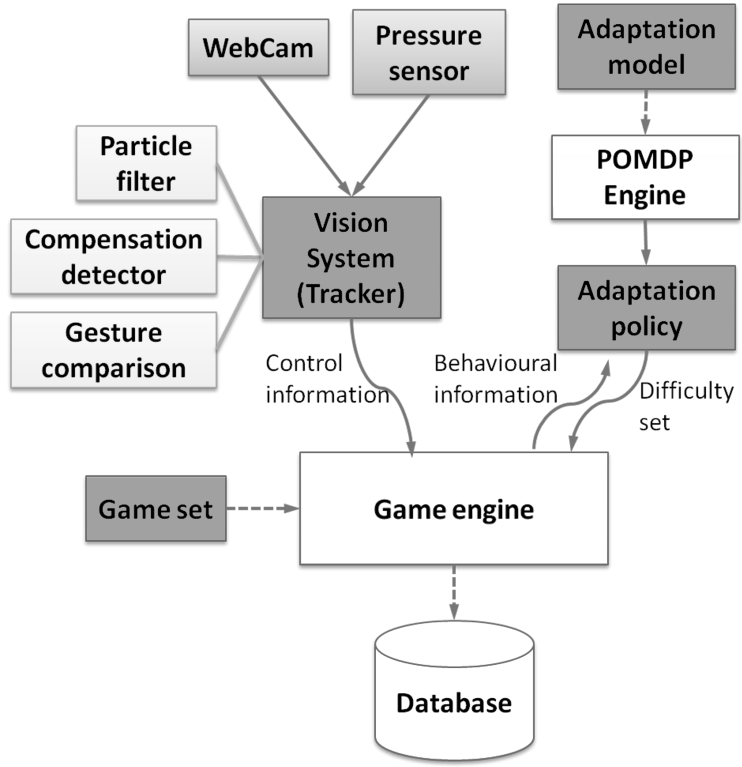

Fig. 2. Gesture Therapy system architecture. The major elements include the monocular vision tracking system which in addition incorporates the information from the pressure sensor, the game engine (Torque) responsible for the animation of the game set and the adaptation module resolved with a POMDP engine based on Perseus algorithm. Further description can be found in the main text. White elements correspond to external engines, dark grey boxes encapsulate platform modules, mid grey boxes represent hardware elements and light grey boxes correspond to submodules.

relying on the aforementioned POMDP. This decision is then communicated back to the game engine.

The system is built upon a game engine (Torque, Garage Games, USA) [56] and a Markov Decision Process engine (Perseus) [57]. The vision module (C++) writes system inputs in a shared memory address which is read by the game engine. The game engine (Torque, Garage Games, USA) [56] outputs system usage to a MySQL database including information such as speed and smoothness of trajectory. The gameplay automatically adapts to the user progress capitalizing on the afore described POMDP [55]. The rules of an adaptation model is specified in MDP engine Perseus [57], which computes the optimum adaptation policy which is then communicated to the game engine. A JNI ( $+++/ J a v a)$ interface permits communication between the game engine and the POMDP.

\section{B. The game set}

Games for rehabilitation should comply with particular game design principles [9], [13], [55]. So far, we have developed a set of three games adhering to these principles (see Fig. 3).

- Steak: The user must "turn" a steak in a grill before it burns. The steak changes its colour to a darker brown as time passes. A virtual hand must touch (i.e. turn) the steak in the grill to prevent it from burning. After the steak is touched, a new steak appears somewhere else in the grill. The distance at which the new steaks appear is automatically selected by the adaptation module. The time it takes before the steak burns can be adjusted. The 


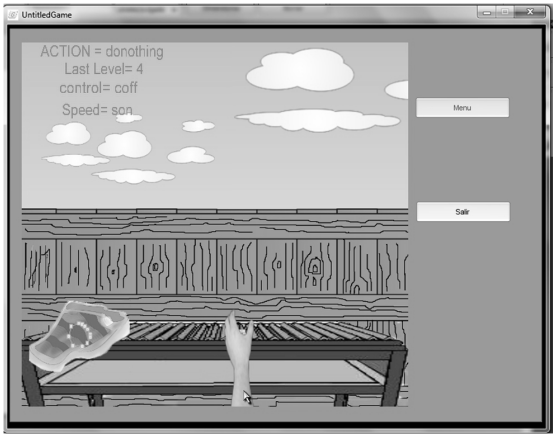

(a) Steak

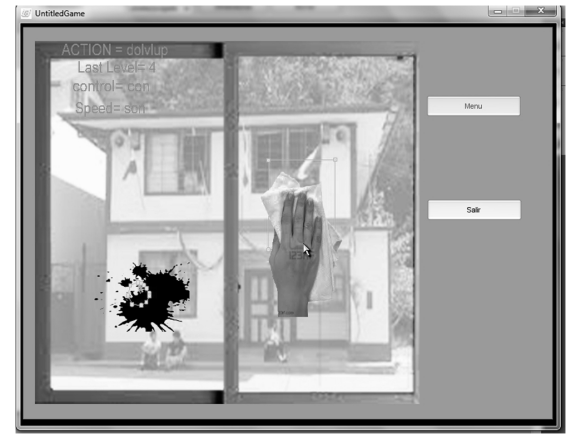

(b) Clean Window

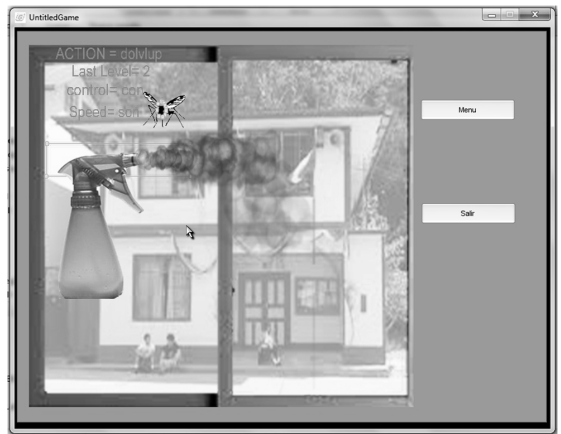

(c) Fly Killer

Fig. 3. The game set. Left: Steak, Middle: Clean Window, Right: Fly killer. Each game is designed according to a set of criteria thought to be beneficial for rehabilitation and aims to promote different rehabilitatory movements. Full description of the games is given in the main text.

game focuses in an abduction/adduction movement of the arm. This game is intended for early therapy.

- Clean window: A hand holding a cloth wipes a window glass to remove stains. As the old stains are wiped, new stains appear randomly over the window. Game difficulty is modulated by means of adjusting the distance at which the new stains appear. The distance (Euclidean) is measured pixels from the screen position of the previous stain. Similarly to the game steak the aim is to touch the goal, in this case the stain, but differently from the steak game the allowed movement in this game is two-directional; abduction/adduction and elevation/depression. This is thus a game for late rehabilitation.

- Fly Killer: In this game, the patient armed with an insecticide sprayer tries to kill a buzzing mosquito that approaches at different heights. The task goal is to kill the mosquito before it comes too close to the hand. The patient is armed with an insecticide sprayer that s/he must align in height with the mosquito and then press the gripper to spray the insecticide. The mosquito speed and the pressure necessary to spray are configurable parameters. The vertical distance at which the next mosquito appears is dictated by the adaptation policy. The game favours elevation/depression movements and power gripping.

Suitability of this game set has been assessed by therapists at the National Institute of Neurology and Neurosurgery in Mexico. Positive aspects cited by the clinicians were (i) the ease of use both for the clinician and the patient, (ii) the possibility to change the game duration as they are often delivered in short blocks during the therapy session, (iii) the reward feedback at the end of the game was also stressed as an important element, and (iv) the trunk compensation feature which was suggested to be responsible for posture correction consequence of the greater postural awareness by the patient. Also, and in particular of the clean window game clinicians welcomed the wider amplitude of the movements. Nonetheless, the rehabilitation therapists demanded more game variety, avatar personalization, patient history storing, more rewards to excite the limbic system in the brain, metrics to evaluate attention and coordination and easier timing control. And thinking about the application of GT for children with cerebral palsy the therapists recommended to develop new games

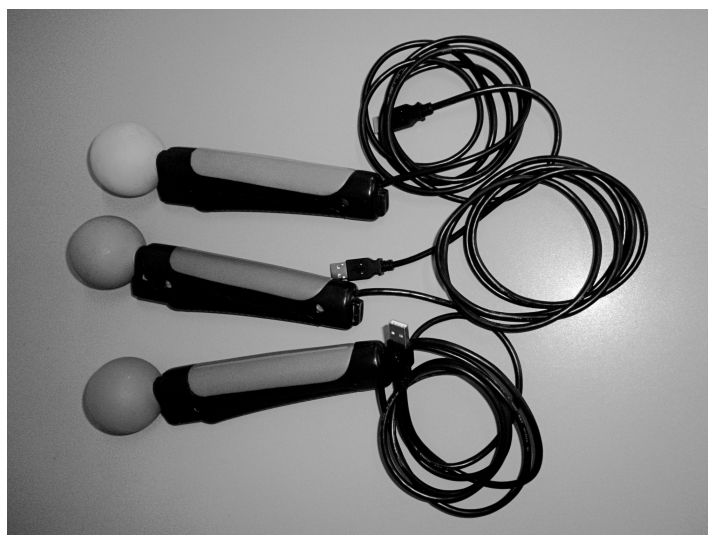

(a) Gripper

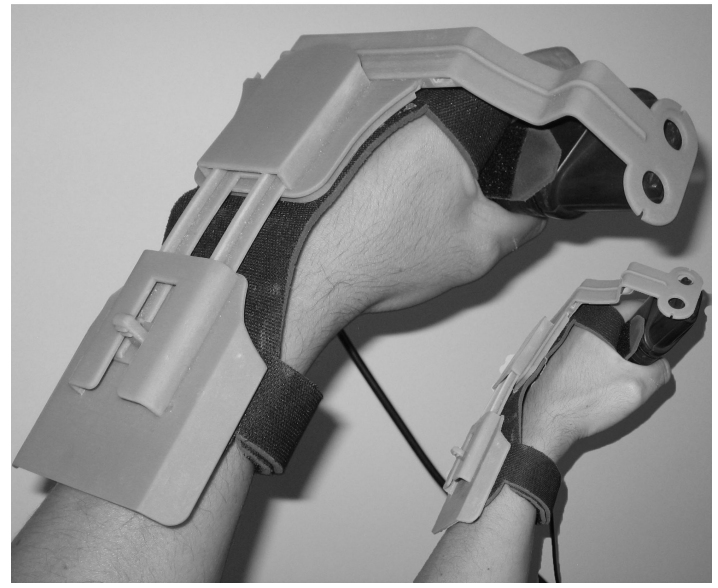

(b) Hand support

Fig. 4. The Gesture Therapy platform controller. Top: grippers for arm rehabilitation. Bottom: harness for people too paretic to hold the gripper.

especially themed for kids and perhaps to disguise them in an interactive storytelling. We are in the process of improving and enlarging our game set.

\section{The controller; the gripper}

The gripper (see Fig. 4a) has a main hollow plastic body that provides structural support, a pressure sensor in the front and a resting zone in the rear for ergonomic handling [58]. The gripper is complemented with communication electronics 
to transmit grip strength and an USB interface for power supply. A sphere made of matte material facilitates visual identification. For patients too paretic to hold the gripper an additional support (see Fig. 4b) is affixed to the forearm and ensures the patient holds the gripper safely and further permits correction of the wrist position with respect to the forearm during the execution of the rehabilitation exercises. All clinical trials so far have been carried out with this gripper.

\section{Tracker}

The tracking algorithm is based on a particle filter which recognises the tracking target based on colour and texture features [2], [3]. Particle filters are a probabilistic technique based on Monte Carlo methods. They maintain a sampled representation of the target object's distribution, where each sample is a particle, that is a point in a state space with a certain mass depending on its significance. The particle collection evolves with time with the incorporation of new observations, i.e. colour and texture in our case, and the prediction of the object movement. On every iteration of the filter, a new generation of particles arises incorporating the new positions and their probabilistic beliefs based upon the observations. Implementation is based on OpenCV [59] with modifications to ensure compatibility with a large search space i.e. the combination of patches sizes, patches locations within the frame, size of the target to estimate depth and target location given the video resolution. To avoid break down, the number of particles and the size of the training zone are both configurable parameters from the graphical user interface. For initializing the tracking, it is only necessary to take a sample image of the target, e.g. the gripper's ball. Upon selecting the training sample the tracking process begins and the selected target object can now move freely. The system is robust to partial occlusion and even to the target object momentarily leaving the scene. The tracker processes a 320x240 pixels live stream video at $30 \mathrm{~Hz}$. The controller is tracked in $2 \mathrm{D}$ and depth is estimated based on the volume of the particle filter distribution surrogating object size.

In addition to the naive training a simple calibration is necessary before each session. In order to calibrate the system, the user moves his arm from one end to the opposite end of the region encompassing the maximum area of movement that he can reach. The calibration process adjusts the real scene space coordinates to the games' space boundaries.

\section{E. Adaptation}

A POMDP is used to adapt the difficulty level from speed and deviation from smooth motion paths [55]. Our POMDP implementation is built upon symbolic-Perseus algorithm [57] and software [60] that allows factored representations of state and observation variables. The user dexterity is derived from two observable variables; Control and Speed from which the hidden variable Performance is estimated. Control is determined as the deviation in the trajectory from a straight movement from origin -cursor position at the instant of target popping- to target location. For this, the travelled path is reconstructed from the visited pixels. The total length of the

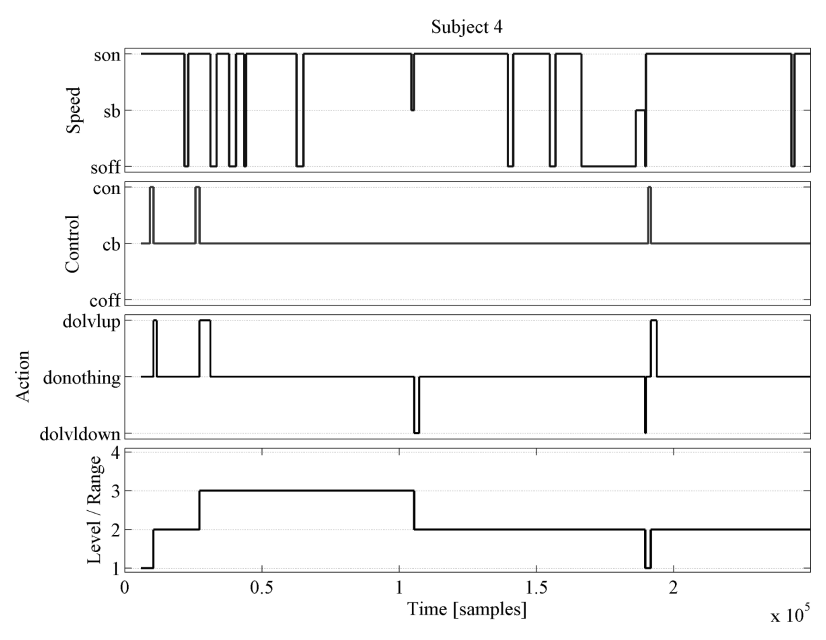

Fig. 5. Exemplary timecourse of the observable variables (speed and control), the action taken by the decision algorithm (action) and the output (level) for an exemplary subject. The level of the game is modified according to the values of observations from which user performance is inferred.

travelled path from origin cursor position at the instant of target popping- to target location is calculated as the sum of the differential straight lines from one visited pixel to the next visited pixel. Deviation is calculated by comparing this total path length with the length of an ideal straight path going from origin to target location. The more deviation from this straight path, the less control. Control is considered in 3 ranges; low, normal and good. Speed corresponds to the ratio of distance along the optimum path and execution time. Similarly to control, speed is also considered in 3 ranges; low, normal and good. Control and speed are combined to decide about performance of the user -bad, good, and outstanding-. The user's performance in turn governs the game difficulty. The game Difficulty can take three possible values: easy, medium, and hard. The level of performance dictates the action of the system, i.e. increase, keep or decrease game difficulty. Decisions are made in order to keep the difficulty level in balance with respect to the performance level. Fig. 5 provides an example of the behaviour of the adaptation algorithm during a typical session. We are now expanding on this work by developing a dynamic adaptation algorithm that can change its underlying decision policy on-line during the therapy administration using reinforcement learning [61].

\section{FEASIBILITY PILOT}

In order to evaluate the feasibility of the platform in its current form, a small feasibility pilot has been carried out at the National Institute of Neurology and Neurosurgery in Mexico City. Kinematic data from 6 chronic stroke patients while using the described system was collected over a period of one month. All participants were concurrently receiving physical therapy, and voluntarily agreed to participate. Table II summarizes the cohort characteristics. During this period, usage of the GT platform was determined by therapist criterion, and number of sessions with GT for each participant varied from 1 to 4 . All three games were played at least once, and game timing 


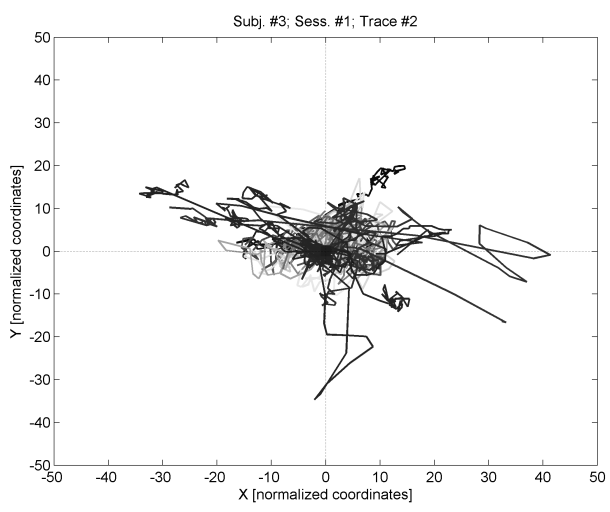

(a) First session; Subject 3

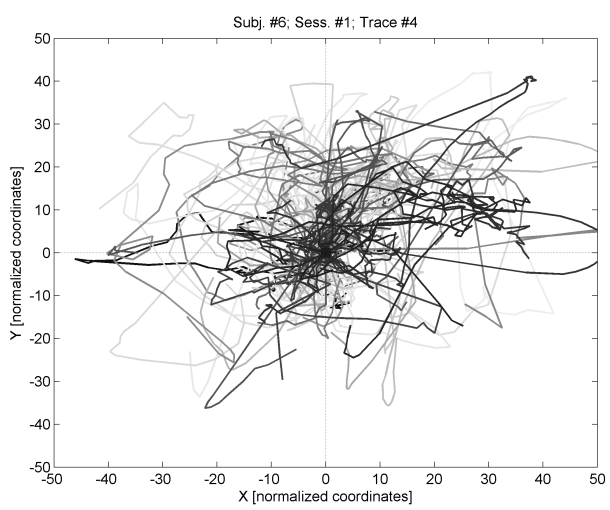

(c) First session; Subject 6

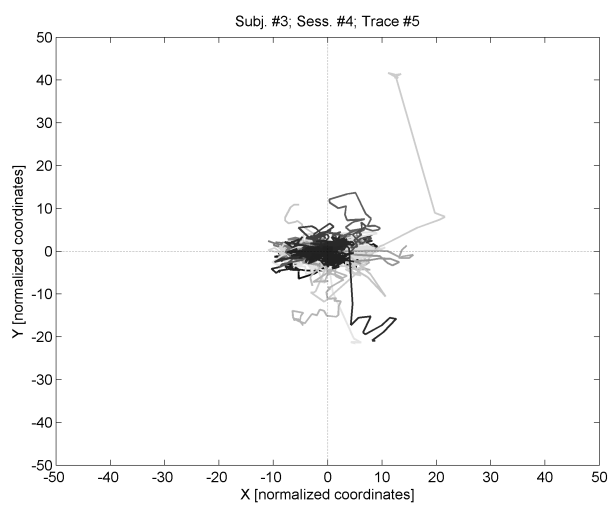

(b) Last session; Subject 3

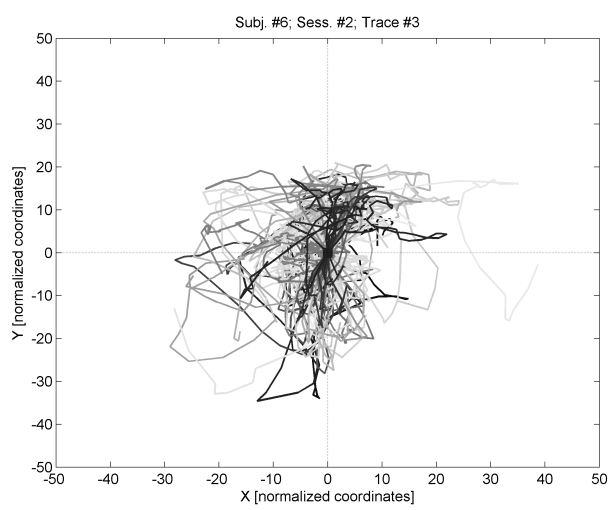

(d) Last session; Subject 6

Fig. 6. Exemplary kinematic traces for two different subjects illustrating the longitudinal differences in control from first to last session. Top: Subject 3, the one with the largest improvement in control. Bottom: Subject 6 , the one with poorest control performance. For the sake of visualization, target locations have all been centered to normalized coordinates $[0,0]$. Shades of grey facilitate distinction of different traces, but have no other meaning associated. Each subplot represents 3 minutes of gaming time.

TABLE II

SUMMARY OF RESULTS OF THE FEASIBILITY PILOT.

\begin{tabular}{|l|l|}
\hline \hline & Group \\
\hline \hline Age [years] $(\mu \pm \sigma)$ & $52.0 \pm 14.66$ \\
Gender & 5 female, 1 male \\
Months post-stroke $(\mu \pm \sigma)$ & $29.5 \pm 13.47$ \\
Hemiparetic side & 6 right, 0 left \\
Fugl-Meyer at start $(\mu \pm \sigma)$ & $37 \pm 5.56$ \\
Gaming time [min] ${ }^{1}(\mu \pm \sigma)$ & $53 \pm 29.06$ \\
\hline
\end{tabular}

${ }^{1}$ Gaming time refers strictly to time spent on the games. The GT sessions require some time for the calibration, switching games and clinicians feeding back to the adaptation module, thus the total therapy time is actually larger than strictly the gaming time.

was pre-set to 3 minutes (although this can be altered by the therapist at any time).

Figure 6 illustrates exemplary traces of kinematic data. Longitudinal differences in control from first to last session can be appreciated for the subject with the largest improvement in control (Subject 3), but not for a subject not exhibiting control improvement (Subject 6). Performance results from the feasibility study are summarized in Figure 7. The two-tailed Wilcoxon sign rank for paired observations at $5 \%$ significance level was used to test for statistical significance in all three performance metrics; number of targets per time unit, control and speed. Neither changes in targets per time unit $(p=1)$, control $(\mathrm{p}=0.125)$ nor speed $(\mathrm{p}=0.3125)$ were found significant. Different plausible and non exclusive explanations can be stated. First, the amount of therapy received in this feasibility study was short and insufficient to permit appreciation of differences. Note that this feasibility dose is lower than that administered in our clinical trials for earlier versions of the platform [4], [5]. Second, the game challenge adaptation mechanism with its current policy emphasizing coupled progress of speed and control, favours a slower but surer progress, and may be responsible for some of the drops in speed and increases in control. Finally, the adaptation module increases the challenge by means of enlarging the distance between consecutive targets as the patient progresses. Therefore, the inherently longer paths from the user's avatar onset position to the target location is a candidate for explaining the apparent lack of progress in terms of targets per time unit.

\section{CONCLUSIONS}

Gesture Therapy was conceived as a solution particularly suitable for home usage, and as such, it has a very low cost. Among the main features of this platform are (i) its game 


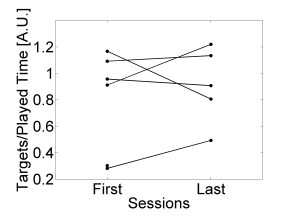

(a) Targets per time unit

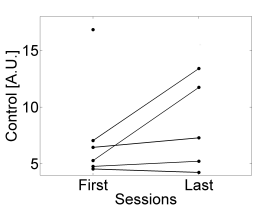

(b) Control

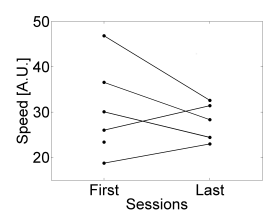

(c) Speed
Fig. 7. Performance results from the feasibility study comparing first vs last session. One of the subjects only completed 1 session. Left: Targets per unit time. Middle: Control Right: Speed.

set developed using game design criteria considered to be relevant for rehabilitation, (ii) its innovative controller, (iii) its monocular 3D tracking system, (iv) its capability to detect compensatory movements also from the vision system, and (v) its adaptation module which capitalizes on decision-theoretic models to fit the patient progress. Clinical trials carried out over an earlier version of the platform [4], [5] suggest that GT, might support motor recovery comparable to that of occupational therapy to stroke survivors but increasing motivation as measured by the Intrinsic Motivation Inventory as well as subjective comments from the patients. The feasibility pilot described in Sect IV using the platform version presented in Sect III provides preliminary evidence of the usefulness of the GT application with its latest developments.

The most important contribution of GT are as follows. First, we have developed a controller specifically designed for stroke patients that among other features do not require elbow rest, can be used by patients with very different degree of paresis [5], and permit gripping. Second, a novel 3D monocular tracking system capable of estimating depth from a single webcam. We are in the process of obtaining patents for the gripper and the monocular tracking system. Third, we have exploited probabilistic models from artificial intelligence to produce an intelligent game set that adapts game challenge to patients in-game performance. Fourth, through our (earlier) clinical trials and current feasibility pilot, we have contributed to the growing evidence of the usefulness and validity of virtual reality based therapies, and in particular of GT. Finally, we have provided a picture of how the brain responds to GT [5], [62]. In this sense we are only starting to understand the therapy induced cortical reorganization associated with motor recovery. We are now adding user profiling capabilities, enlarging our game set and improving the user interface. We are also planning to use transfer learning to provide intersession adaptation and therapy planning.

In addition, we are now establishing the validity of the platform for disabilities in children resulting from cerebral palsy. This is a multicenter study that will elucidate the clinical benefits of GT in circumstances other than stroke and adult population. Preliminary subjective appreciation is that children enjoy the VR games more than adults, but they require continuous supervision while playing the games so they do perform the exercises correctly. We conjecture that perhaps incorporating a virtual therapist that monitors the child movements and encourages the correct movements and discourages erroneous execution may be beneficial.

\section{ACKNOWLEDGMENT}

The authors would like to thank H. Avilés-Arriaga, S. Ávila-Sansores, J. Oropeza-Salas, I. Sánchez and L. Palafox who have actively collaborated in the building of the Gesture Therapy platform or helped during the clinical trials. This work has been funded by the following projects: SALUD2007-C01-70074 from the CONACYT, Project 95185 from the FONCICYT (European Union-Mexico), the MARS-RERC program of the Rehabilitation Institute of Chicago, and the National Institute for Disability and Rehabilitation Research Rehabilitation Engineering Research Center on Rehabilitation Robotics and Telemanipulation, "Machines Assisting Recovery after Stroke" Grant \#: H133E070013.

\section{REFERENCES}

[1] P. Langhorne, F. Coupar, and A. Pollock, "Motor recovery after stroke: a systematic review," Lancet Neurology, vol. 8, pp. 741-754, 2009.

[2] L. E. Sucar, R. Leder, J. Hernández, I. Sánchez, and G. Azcárate, "Clinical evaluation of a low-cost alternative for stroke rehabilitation," in IEEE International Conference on Rehabilitation Robotics (ICORR 2009). Kyoto International Conference Center, Japan: IEEE, 23-26 June 2009, pp. 863 - 866.

[3] L. E. Sucar, A. Molina, R. Leder, J. Hernández, and I. Sánchez, "Gesture therapy: a clinical evaluation," in 3rd International Conference of the Institute for Computer Sciences, Social-Informatics and Telecommunications Engineering (ICST) on Pervasive Computing Technologies for Healthcare (Pervasive Health 2009). London, UK: IEEE, 1-3 APR 2009, pp. 1-5.

[4] L. E. Sucar, R. Luis, R. Leder, J. Hernández, and I. Sánchez, "Gesture therapy: A vision-based system for upper extremity stroke rehabilitation," in 32nd Annual International Conference of the IEEE Engineering in Medicine and Biology Society (EMBS). Buenos Aires, Argentina: IEEE, 31st AUG -4th SEP 2010, pp. 3690 - 3693.

[5] F. Orihuela-Espina, I. Fernández del Castillo, L. Palafox, E. Pasaye, I. Sánchez-Villavicencio, R. Leder, J. Hernández-Franco, and L. E. Sucar, "Neural reorganization accompanying upper limb motor rehabilitation from stroke with virtual reality-based gesture therapy," Topics in Stroke Rehabilitation, vol. 20, no. 3, pp. 197-209, 2012.

[6] G. Kwakkel, "Intensity of practice after stroke: More is better," Schweizer Archiv für Neurologie und Psychiatrie, vol. 160, no. 7, pp. 295-298, 2009.

[7] C. E. Lang, J. MacDonald, and C. Gnip, "Counting repetitions: an observational study of outpatient therapy for people with hemiparesis post-stroke," Journal of Neurologic Physical Therapy, vol. 31, pp. 310, MAR 2007.

[8] M. K. Holden, "Virtual environments for motor rehabilitation: Review," CyberPsychology \& Behavior, vol. 8, no. 3, pp. 187-211, 2005.

[9] J. W. Burke, M. D. J. McNeill, D. K. Charles, P. J. Morrow, J. H. Crosbie, and M. S. M., "Serious games for upper-limb rehabilitation following stroke," in 2009 Conference in Games and Virtual Worlds for Serious Applications, G. Rebolledo-Mendez, F. Liarokapis, and S. de Freitas, Eds., Coventry, UK., 23-24 MAR 2009, pp. 103-110.

[10] S. K. Subramanian, C. B. Lourenco, G. Chilingaryan, H. Sveistrup, and M. F. Levin, "Arm motor recovery using a virtual reality intervention in chronic stroke: randomized control trial," Neurorehabilitation and Neural Repair, vol. 27, no. 1, pp. 13-23, 2013.

[11] R. Colombo, F. Pisano, A. Mazzone, C. Delconte, S. Micera, M. C. Carrozza, P. Dario, and G. Minuco, "Design strategies to improve patient motivation during robot-aided rehabilitation," Journal of NeuroEngineering and Rehabilitation, vol. 4, no. 1, p. 3 (12 pp), FEB 2007. [Online]. Available: http://www.jneuroengrehab.com/content/4/1/3

[12] K. Harris and D. Reid, "The influence of virtual reality play on children's motivation," The Canadian Journal of Occupational Therapy, vol. 72, no. 1, pp. 21-29, FEB 2005.

[13] G. Alankus, A. Lazar, M. May, and C. Kelleher, "Towards customizable games for stroke rehabilitation," in ACM Conference on Human Factors in Computing Systems (CHI) Therapy and Rehabilitation, E. Mynatt, G. Fitzpatrick, S. Hudson, K. Edwards, and T. Rodden, Eds. Atlanta, Georgia, USA: ACM, 10-15 APR 2010, pp. 2113-2122. 
[14] S. V. Adamovich, G. G. Fluet, A. Mathai, Q. Qiu, J. Lewis, and A. S. Merians, "Design of a complex virtual reality simulation to train finger motion for persons with hemiparesis: a proof of concept study," Journal of NeuroEngineering and Rehabilitation, vol. 6, p. 28 (10 pp.), 2009.

[15] A. S. Merians, D. Jack, R. Boian, M. Tremaine, G. C. Burdea, S. V. Adamovich, M. Recce, and H. Poizner, "Virtual reality-augmented rehabilitation for patients following stroke," Physical Therapy, vol. 82, no. 9, pp. 898-915, SEP 2002.

[16] G. Burdea, V. Popescu, V. Hentz, and K. Colbert, "Virtual reality-based orthopedic telerehabilitation," IEEE Transactions on Rehabilitation Engineering, vol. 8, no. 3, pp. 430-432, SEP 2000.

[17] D. J. Reinkensmeyer, C. T. Pang, J. A. Nessler, and C. C. Painter, "Web-based telerehabilitation for the upper extremity after stroke," IEEE Transactions on Neural Systems and Rehabilitation Engineering, vol. 10, no. 2, pp. 102-108, JUN 2002.

[18] K. E. Laver, G. Stacey, S. Thomas, J. E. Deutsch, and M. Crotty, "Virtual reality for stroke rehabilitation," Cochrane Database of Systemic Reviews, vol. 9, p. 70 pp., 2011.

[19] A. S. Rizzo and G. J. Kim, "A SWOT analysis of the field of virtual reality rehabilitation and therapy," Presence, vol. 14, no. 2, pp. 119-146, Apr. 2005.

[20] J. J. LaViola Jr., "A discussion of cybersickness in virtual environments," Special Interest Group on Computer Human Interaction (SIGCHI) Bulletin, vol. 32, no. 1, pp. 47-56, 2000.

[21] F. D. Rose, E. A. Attree, B. M. Brooks, and D. A. Johnson, "Virtual environments in brain damage rehabilitation: A rationale from basic neuroscience," Studies in Health Technology and Informatics, vol. 58, pp. 233-242, 1998 .

[22] E. Todorov, R. Shadmehr, and E. Bizzi, "Augmented feedback presented in a virtual environment accelerates learning of a difficult motor task," Journal of Motor Behaviour, vol. 29, no. 2, pp. 147-158, 1997. [Online]. Available: http://dx.doi.org/10.1080/00222899709600829

[23] F. D. Rose, E. A. Attree, B. M. Brooks, D. M. Parslow, P. R. Penn, and N. Ambihaipahan, "Training in virtual environments: transfer to real world tasks and equivalence to real task training," Ergonomics, vol. 43, no. 4, pp. 494-511, 2000. [Online]. Available: http://dx.doi.org/10.1080/001401300184378

[24] B. M. Brooks, J. E. McNeill, F. D. Rose, R. J. Greenwood, E. A. Attree, and A. G. Leadbetter, "Route learning in a case of amnesia: a preliminary investigation into the efficacy of training in a virtual environment," Neuropsychological rehabilitation, vol. 9, no. 1, pp. 63-76, 1999.

[25] J. S. Webster, P. T. McFarland, L. J. Rapport, B. Morrill, L. A. Roades, and P. S. Abadee, "Computer-assissted training for improving wheelchair mobility in unilateral neglect patients," Archives of Physical Medicine and Rehabilitation, vol. 82, pp. 769-775, 2001.

[26] D. L. Jaffe, D. A. Brown, C. D. Pierson-Carey, E. L. Buckley, and H. L. Lew, "Stepping over obstacles to improve walking in individuals with poststroke hemiplegia," Journal of Rehabilitation Research and Development, vol. 41, no. 3A, pp. 283-292, MAY/JUN 2004.

[27] M. P. Dijkers, P. C. deBear, R. F. Erlandson, K. Kristy, D. M. Geer, and A. Nichols, "Patient and staff acceptance of robotic technology in occupational therapy: A pilot study," Journal of Rehabilitation Research and Development, vol. 28, no. 2, pp. 33-44, 1991.

[28] C. G. Burgar, P. S. Lum, P. C. Shor, and M. v. d. Loos, "Development of robots for rehabilitation therapy: the Palo Alto VA/Stanford experience," Journal of Rehabilitation Research and Development, vol. 37, no. 6, pp. 663-673, NOV/DEC 2000.

[29] M. J. Johnson, M. v. d. Loos, C. G. Burgar, and L. J. Leifer, "Driver's seat: Simulation environment for arm therapy," in 6th International Conference on Rehabilitation Robotics (ICORR'1999), M. v. d. Loos, Ed., Stanford, California, USA, 1-2 JUL 1999, pp. 227-234.

[30] H. I. Krebs, T. Brashers-Krug, S. L. Rauch, C. R. Savage, N. Hogan, R. H. Rubin, A. J. Fischman, and N. M. Alpert, "Robot-aided functional imaging: application to a motor learning study," Human Brain Mapping, vol. 6 , pp. 59-72, 1998

[31] D. J. Reinkensmeyer, L. E. Kahn, M. Averbuch, A. McKenna-Cole, B. D. Schmit, and W. Z. Rymer, "Understanding and treating arm movement impairment after chronic brain injury: progress with the ARM guide," Journal of Rehabilitation Research and Development, vol. 37, no. 6, pp. 653-662, NOV/DEC 2000.

[32] D. J. Reinkensmeyer, C. T. Pang, J. A. Nessler, and C. C. Painter, "Java therapy: Web-based robotic rehabilitation," 2001.

[33] M. K. Holden and T. Dyar, "Virtual environment training: a new tool for neurorehabilitation," Neurobiology report, vol. 26, no. 2, pp. 62-71, 2002.

[34] C. Ellsworth and J. Winters, "An innovative system to enhance upperextremity stroke rehabililtation," in 2nd Joint Engineering in Medicine and Biology Society and Biomedical Engineering Society (EMBS/BMES) Conference, J. W. Clark, L. V. McIntire, P. Y. Ktonas, A. G. Mikos, and F. H. Ghorbel, Eds., vol. 3. Houston, Texas, USA: IEEE, 23-26 OCT 2002, pp. $2367-2368$.

[35] R. Loureiro, F. Amirabdollahian, M. Topping, B. Driessen, and W. Harwin, "Upper limb robot mediated stroke therapy - GENTLE/s approach," Autonomous Robots, vol. 15, pp. 35-51, 2003.

[36] M. J. Johnson, M. Trickey, E. Brauer, and X. Feng, "Theradrive: a new stroke therapy concept for home-based, computer-assissted motivating rehabilitation," in 26th Annual International Conference of the IEEE Engineering in Medicine \& Biology Society (EMBS), D. Hudson and Z.-P. Liang, Eds., San Francisco, CA, USA, 1-5 SEP 2004, pp. 4844 4847.

[37] P. L. Weiss, D. Rand, N. Katz, and R. Kizony, "Video capture virtual reality as a flexible and effective rehabilitation tool," Journal of NeuroEngineering and Rehabilitation, vol. 1, p. 12 pp, 2004.

[38] S. H. Jang, S. H. You, M. Hallet, Y. W. Cho, C.-M. Park, S.-H. Cho, H.-Y. Lee, and T.-H. Kim, "Cortical reorganization and associated functional motor recovery after virtual reality in patients with chronic stroke: an experimenter-blind preliminary study," Archives of Physical Medicine and Rehabilitation, vol. 86, pp. 2218-2223, 2005.

[39] K. August, D. Bleichenbacher, and S. Adamovich, "Virtual reality physical therapy: A telerehabilitation tool for hand and finger movement exercise monitoring and motor skills analysis," in Proceedings of the IEEE 31st Annual Northeast Bioengineering Conference. New Jersey, USA: IEEE, 2-3 APR 2005, pp. 73-74.

[40] R. Kizony, P. L. Weiss, M. Shahar, and D. Rand, "Theragame - a home based virtual reality rehabililtation system," in 6th International Conference on Disability, Virtual Reality and Associated Technologies (ICDVRAT'2006), T. Brooks and S. Cobb, Eds., Esbjerg, Denmark, 1820 SEP 2006, pp. 209-214.

[41] R. J. Sanchez, J. Liu, S. Rao, P. Shah, R. Smith, T. Rahman, S. C. Cramer, J. E. Bobrow, and D. J. Reinkensmeyer, "Automating arm movement training following severe stroke: functional exercises with quantitative feedback in gravity-reduced environment," IEEE Transactions on Neural Systems and Rehabilitation Engineering, vol. 14, no. 3, pp. 378-389, SEP 2006.

[42] K. Morrow, C. Docan, G. Burdea, and A. Merians, "Low-cost virtual rehabilitation of the hand for patients post-stroke," in International Workshop on Virtual Rehabilitation, G. Burdea, P. T. Weiss, J. Cottraux, and A. S. Rizzo, Eds. New York, USA: IEEE, 2006, pp. 6-10.

[43] M. Huber, B. Rabin, C. Docan, G. Burdea, M. E. Nwosu, M. Abdelbaky, and M. R. Golomb, "PlayStation 3-based tele-rehabilitation for children with hemiplegia," in Virtual Rehabilitation, J. Fung and P. T. Weiss, Eds. Vancouver, BC, Canada: IEEE, 25-27 AUG 2008, pp. 105-112.

[44] M. Ma and K. Bechkoum, "Serious games for movement therapy after stroke," in IEEE International Conference on Systems, Man and Cybernetics, 2008 (SMC 2008), Singapore, 12-15 Oct 2008, pp. 18721877.

[45] J. E. Deutsch, M. Borbely, J. Filler, K. Huhn, and P. Guarrera-Bowlby, "Use of low-cost, commercially available gaming console (wii) for rehabilitation of an adolescent with cerebral palsy," Physical Therapy, vol. 88 , no. 10, pp. 1196-1207, 2008.

[46] A.-S. Alklind Taylor, P. Backlund, H. Engström, M. Johannesson, and M. Lebram, "Gamers against all odds," in Edutainment '09 Proceedings of the 4th International Conference on E-Learning and Games: Learning by Playing. Game-based Education System Design and Development, M. Chang, R. Kuo, Kinshuk, G.-D. Chen, and M. Hirose, Eds., vol. Lecture Notes in Computer Science 5670. Springer-Verlag, 2009, pp. $1-12$.

[47] J. Hoey, A. Monk, and A. Mihailidis, "People, sensors, decisions: Customizable and adaptive technologies for assistance in healthcare," in POMDP Practitioners Workshop: solving real-world POMDP problems at 20th International Conference on Automated Planning and Scheduling (ICAPS 2010), Toronto, Canada, 12 MAY 2010, p. 9 pp.

[48] Y. Chen, N. Lehrer, H. Sundaram, and T. Rikakis, "Adaptive mixed reality stroke rehabilitation: System architecture and evaluation metrics," in Proceedings of the first annual ACM SIGMM conference on Multimedia systems (MMSys'2010), W.-c. Feng, Ed., Phoenix, Arizona, USA, 22-23 FEB 2010, pp. 293-304.

[49] S. Shiri, U. Feintuch, A. Lorber-Haddad, E. Moreh, D. Twito, M. Tuchner-Arieli, and Z. Meiner, "A novel virtual reality system integrating online self-face viewing and mirror visual feedback for stroke rehabilitation: rationale and feasibility," Topics in Stroke Rehabilitation, vol. 19, no. 4, p. 277286, JUL-AUG 2012.

[50] D. Tsoupikova, N. Stoykov, D. Kamper, and R. Vick, "Virtual reality environment assisting post stroke hand rehabilitation: case report," 
Studies in Health Technology and Informatics, vol. 184, pp. 458-64, 2013.

[51] H. Mousavi Hondori, M. Khademi, L. Dodakian, S. C. Cramer, and C. V. Lopes, "A spatial augmented reality rehab system for post-stroke hand rehabilitation," Studies in Health Technology and Informatics, vol. 184, pp. 279-285, 2013.

[52] M. Steinisch, M. G. Tana, and S. Comani, "A post-stroke rehabilitation system integrating robotics, vr and high-resolution eeg imaging," IEEE Transactions on Neural Systems and Rehabilitation Engineering, vol. Accepted, 2013.

[53] P. Viola and M. Jones, "Robust real-time object detection," in 2nd International workshop on Statistical and Computational Theories of Vision - Modeling, Learning, Computing and Sampling, S.-C. Zhu, A. Yuille, and D. Mumford, Eds., Vancouver, Canada, 13th JUL 2001 p. 25 pp.

[54] M. F. Levin, "Can virtual reality offer enriched environments for rehabilitation?" Expert Reviews of Neurotherapeutics, vol. 11, no. 2, pp. 153-155, 2011.

[55] H. Avilés, R. Luis, J. Oropeza, F. Orihuela-Espina, R. Leder, J. Hernández-Franco, and E. Sucar, "Gesture therapy 2.0: Adapting the rehabilitation therapy to the patient progress," in Workshop on Probabilistic Problem Solving in Biomedicine in 13th Conference on Artificial Intelligence in Medicine (AIME'11), A. Hommerson and P. Lucas, Eds., Bled, Slovenia, JUL 2011, pp. 3-14.

[56] "Torque game engine. http://www.garagegames.com/products/tge."

[57] "Symbolic perseus.http://www.cs.uwaterloo.ca/ ppoupart/software.html."

[58] L. E. Sucar, R. Luis-Velasquez, D. Carrillo-López, J. Hernández-Franco, and R. E. Cordero-Cesar, "Mango portátil para rehabilitación de extremidades superiores," International PCT Patent PCT11/140, 2011.

[59] OpenCV. http://opencv.org/. [Online]. Available: http://opencv.org/

[60] J. Hoey, P. Poupart, A. v. Bertoldi, T. Craig, C. Boutilier, and A. Mihailidis, "Automated handwashing assistance for persons with dementia using video and a partially observable markov decision process," Computer Vision and Image Understanding, vol. 114, p. 503519, 2010.

[61] S. Ávila-Sansores, F. Orihuela-Espina, and L. E. Sucar, "Patient tailored virtual rehabilitation," in International Conference on NeuroRehabilitation (ICNR'2012), J. L. Pons, D. Torricelli, and M. Pajaro, Eds. Toledo, Spain: Springer, 14-17 NOV 2012, pp. 879-883.

[62] F. Orihuela-Espina and L. E. Sucar, "Functional reorganization strategies associated to motor rehabilitation gesture therapy," Coordinacin de Ciencias Computacionales. Instituto Nacional de Astrofsica, ptica y Electrnica (INAOE), Technical Report CCC-11-001, JUN 2011.

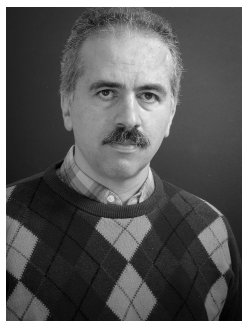

Luis Enrique Sucar (M'82; SM'09) has a Ph.D from Imperial College London, UK, 1992; a M.Sc. from Stanford University, USA, 1982; and a B.Sc. from ITESM, Mexico, 1980. Previously a researcher at the Electrical Research Institute, and professor at ITESM, he is currently Head of Research at INAOE in Mexico. He has been an invited professor at the University of British Columbia, Canada; Imperial College, UK; and INRIA, France. He has more than 150 publications and has directed $16 \mathrm{Ph} . \mathrm{D}$ thesis. Dr. Sucar is Member of the National Research System and the Mexican Science Academy. He has served as president of the Mexican AI Society and as member of the Advisory Board of IJCAI. His main research interests are in graphical models and probabilistic reasoning, and their applications in computer vision, robotics and biomedicine.

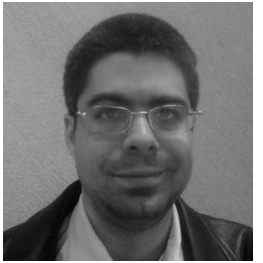

Felipe Orihuela-Espina received his $\mathrm{PhD}$ degree from the University of Birmingham, United Kingdom. He has been a lecturer in the Autonomous University of the State of Mexico and a postdoctoral research associate at Imperial College London from 2007 to 2010 and at the National Institute for Astrophysics, Optics and Electronics (INAOE) in Mexico from 2010 to 2012 . He is currently a senior lecturer at INAOE and member of the National Research System. His current research interests are in image understanding and interpretation.

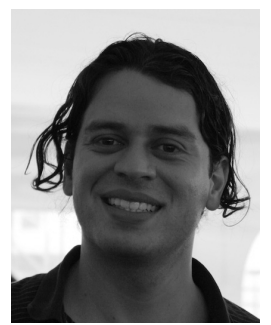

Roger Luis Velazquez received the B.S. degree in Computer Systems Engineering from the Instituto Tecnológico de Minatitlán, Veracruz, MEX, and the M.Sc. degree in Computer Science from INAOE, Puebla, MEX, in 2005 and 2009 respectively. He has worked in an adaptation model applied to stroke rehabilitation using video-games in order to improve the user experience user in rehabilitation exercises.His research interest includes robotics, artificial intelligence, probabilistic reasoning, machine learning, machine vision and adaptive technology.

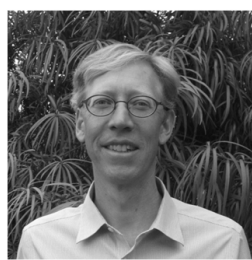

David J. Reinkensmeyer is Professor in the Departments of Mechanical and Aerospace Engineering, Anatomy and Neurobiology, and Biomedical Engineering at the University of California (U.C.) at Irvine. He received the B.S. degree in electrical engineering from the Massachusetts Institute of Technology and the M.S. and Ph.D. degrees in electrical engineering from the U.C. at Berkeley, in 1988 , 1991, and 1993, respectively, studying robotics and the neuroscience of human movement. He carried out postdoctoral studies at the Rehabilitation Institute of Chicago and Northwestern University Medical School from 1994 to 1997, building one of the first robotic devices for rehabilitation therapy after stroke. He became an assistant professor at U.C. Irvine in 1997, establishing a research program that develops robotic and sensor-based systems for movement training and assessment following neurologic injuries and disease. He recently served as the chair of the National Science Foundation initiated International Study on Technology for Mobility, and is the lead researcher for iMove, a collaborative effort at U.C. Irvine focused on using technology to help restore human mobility.

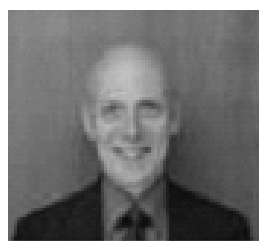

Ronald Leder (chair EMB HxCom 2007-09, MX), Began his professional career in Biomedical Engineering with his first research job at the State University of New York at Stony Brook in 1977. After 12 years of basic and clinical sleep research and as well as clinical practice, he was recruited by the University of Wisconsin Madison to develop and direct a sleep research laboratory for an NIH funded research program. It was there that he met John Webster, Willis Tompkins, and Dan Geisler. While earning his Ph.D. in Electrical and Computer Engineering (2000). Ron became familiar with all 39 IEEE technical societies assisting John Webster on the Wiley Encyclopedia of Electrical and Electronics Engineering. Ron was attracted to Mexico by a Wisconsin colleague to help start a modern neurorehabilitation laboratory and now feels he has a place in Latin America. Neurorehabilitation and sleep \& wakefulness are platforms for studying how the brain works.

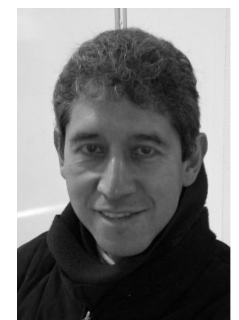

Jorge Hernández-Franco Graduated as medical doctor at the Universidad Autonoma de Mexico in 1985 , got his speciality in rehabilitation medicine in 1989 , and was certified in neurological rehabilitation by the University of Newcastle upon Tyne (U.K) in 1999. Since 1991, he is the head of the rehabilitation ward at the National Neurology and Neurosurgery Institute MVS in Mexico City where he lectures on neurological rehabilitation. He has further lectured on physical therapy in neurological rehabilitation at the American British Cowdray Hospital since 1996. He is the vice-president for Mexico, Central America and the Caribbean of the World Federation for Neurologic Rehabilitation. He is member of the editorial board of the journal Developmental Neurorehabilitation since 2005. 